\title{
PROSA E IMAGINARIO DE LA MODERNIDAD EN EL CUENTO PERUANO DE ENTRESIGLOS
}

\author{
Ricardo Sumalavia \\ Universidad Católica del Perú \\ rsumala@yahoo.com
}

RESUMEN: Habiendo atravesado la experiencia de otro periodo de entresiglos (XX-XXI) conviene revisitar la visión de la modernidad y su practicidad en la sociedad peruana de finales del siglo XIX y principios del XX. El cuento modernista peruano ofrece múltiples entradas para entenderlas contradicciones de una sociedad que se pretende moderna a través de la construcción de una prosa de ficción que anhela asimismo su modernidad.

PALABRAS CLAVE: modernidad, cuento peruano, modernismo

\begin{abstract}
Having gone through the experience of another transition period (from the 20th to the 21 st century) we should revisit the early 19 th C. and late 20 th $\mathrm{C}$. concept of modernity and its effectiveness in the Peruvian society. The Peruvian modernist short story offers several contributions to understand contradictions of a society which intends to be modern by producing works of fiction that also long for modernity.
\end{abstract}

KEYWORDS: modernity, Peruvian short story, modernism

\section{Estilo, realidad y fantasía.}

El crítico peruano Alberto Escobar, en su clásico ensayo "Incisiones en el arte del cuento modernista", a través de un estudio estilístico de los cuentos "Los ojos de Lina" de Clemente Palma, "Mi corbata" de Manuel Beingolea y "El Alfiler" de Ventura García Calderón, destacó como uno de los principales rasgos distintivos de la prosa modernista "el ideal de la lengua y su realización concreta"; idea que complementa del siguiente modo:

[una prosa] cifrada sobre un patrón de lenguaje literario, escrito, de consecuente propósito artístico; pero la norma que rige esa prosa se renueva en el frescor e inventiva del habla coloquial, asimilándola, en un frecuente y feliz cultivo dialógico. (Escobar, 1965: 193)

Es interesante resaltar el aspecto dialógico detectado por Escobar, en tanto que esto nos ayuda a particularizar, por un lado, la prosa modernista peruana, pero también uno de los rasgos de la prosa peruana que se ha mantenido a lo largo de los años. Su reflexión sobre el lenguaje en el cuento pone especial atención en la relación establecida entre el lenguaje coloquial, que por lo demás proviene tanto de los cuadros de costumbres de mediados del XIX, como de las Tradiciones peruanas de Ricardo Palma, y las formas estilizadas que se vieron principalmente reforzadas por las referencias exotistas - que eran un tópico importante entonces -. Es este rasgo quien en buena cuenta dinamiza la prosa de muchos autores de este periodo y el que nos permite detectar los matices estilísticos por los cuales transitaron, yendo desde un registro coloquial hasta otro estilizado. En este espectro podemos mencionar escritores como Clemente Palma, Jorge Miota, Ventura García Calderón, Manuel Beingolea, Enrique A. Carrillo, entre otros.

Escobar resaltó asimismo la plasticidad de las imágenes, todas ellas provenientes de la exaltación de lo sensorial, cargadas de una gran emotividad. Como elemento estilístico también 
destacó un armónico "provecho del ritmo y del movimiento, y de la cadencia musical y el silencio" (Escobar, 1965: 194). Sin duda se trata de una buena interacción en la prosa modernista: la imagen sensitiva que se articula en el propio ritmo de la prosa.

Igualmente, y refiriéndose a los tres cuentos ya mencionados, Escobar da especial relevancia a la percepción de la realidad que se desarrolla en estas historias, la cual bien podemos hacerla extensiva si hablamos de un corpus más amplio del cuento modernista en el Perú. En pasaje final afirma:

En cada caso, la realidad poética reduce el reto de lo fantástico con lo racional y nos asombra en su perenne valor de enigma humano, diario, terreno, y en su función de signo de rebeldía, en revuelta perpetua contra la dimensión dual de nuestra experiencia lógica, de su empecinado deslinde entre la fantasía y la razón. Su realidad, la de ellos, al contrario, emerge cuando se desvanece esa frontera. (Escobar, 1965: 194)

El desvanecimiento de la frontera entre la realidad y la fantasía a la que se alude en la cita anterior es un rasgo recurrente en una gran cantidad de cuentos que se incluyen dentro de esta manifestación modernista peruana. Esta modalidad básicamente se afianzó como una respuesta al positivismo y a todo ese interés cientificista que penetró toda América latina desde finales del siglo XIX; sin embargo es importante anotar que muchos de esos cuentos modernistas, entre los cuales destacamos los de Clemente Palma, estructuran y reelaboran su realidad desde una perspectiva seudocientificista, con personajes cultivadores del ocultismo como disciplina, donde las llamadas ciencias ocultas ofrecen un método riguroso para alcanzar y realizar los imposibles dentro de espacios concretos y reconocibles en el ámbito local. Pero también este seudocientificismo permitió crear realidades en espacios imaginarios futuristas, como en el cuento, "La última rubia" de Palma, en el que su lectura es un claro cuestionamiento a las ideas sobre la civilización, opuestas a las de barbarie - dicotomía de Domingo F. Sarmiento vigente entonces -, en relación directa con los orígenes étnicos de sus personajes. Este tipo de argumentos, como el de este cuento, corresponde a los criterios de modernidad que eran sostenidos por muchos modernistas. A decir de Jorge Larraín:

Para los propulsores de la modernidad de esa época, ella podía lograrse sólo en la medida en que el ethos cultural indo-ibérico fuera radicalmente reemplazado y, para muchos de ellos, esto requería incluso un mejoramiento de la raza. (Larraín, 1997:320)

En el cuento de Clemente Palma que acabamos de citar, el argumento que plantea, desde la perspectiva de un narrador-personaje, es la historia de hombre que desde un futuro remoto nos narra su interés por producir oro, ya que éste había dejado de existir en aquel entonces. Sin embargo, luego de sus investigaciones, que van desde la ciencia futura y la antigua, descubre una fórmula para crear el oro, pero el cual requiere de un componente igualmente extinguido: el cabello de una mujer rubia.

Por un lado, la estrategia para referirse a este seudocientificismo en el cuento de Palma, proviene del interés de los escritores modernistas por apropiarse del saber científico y sus discursos modernizadores en las naciones europeas. Como sostiene Rodríguez Cascante, "la mímesis se convirtió en el paradigma socio-político y cultural de la ciudad letrada latinoamericana" (Rodríguez Cascante, 2004: 247). Clemente Palma, en "La última rubia", inicia su relato con una serie de referencias seudocientíficas - que por otro lado podrían considerarse un antecedente de la ciencia ficción en América Latina - que, desde la perspectiva del futuro, tiene la particularidad considerar a los científicos de fines de XIX como una suerte de continuidad de los alquimistas del pasado. Así, dada una sobreabundancia de datos, se obtiene por efecto observar todos estos procedimientos de creación del oro entre la alternancia de saberes occidentales de diversas épocas. Nos dice, por ejemplo: 
La investigación de la piedra filosofal se hacía con mucho mayor furor que en la remota Edad Media. Un alquimista logró obtener en unas cajas de uranio fosforescente, un depósito de rayos de sol, que sometidos a una presión de 12.000.000.000.000.000.000.000.813 atmósferas, daba una pasta dorada que podía sustituir al oro. (Palma, 2006: 239)

Luego se nos describe otro proceso igual de sorprendente:

Otro alquimista machacaba en un mortero los estambres de la flor de lis, adicionaba bilis de oso polar, y espolvoreaba la mezcla con granalla de selenio o molibdeno. En seguida envolvía este menjurje en barro de coke, y lo sometía a las descargas eléctricas de una bobina de Rumkffork de 20 metros de largo, y obtenía una sustancia amarilla y metálica, que decía ser oro, pero que tenía el inconveniente de oxidarse con la sangre, y disolverse en el amoníaco. (Palma, 2006: 240)

Los intentos fallidos que describe el narrador-personaje en su búsqueda del oro lo lleva a descubrir otra receta, esta vez redactada en latín, en la cual se le exigía un ingrediente particular: "Tomarás un cabello de mujer rubia (rubicundae faemine capellae)" (Palma, 2006: 240)

Es en este momento que se origina el conflicto del cuento en tanto que se nos revela que las mujeres rubias también se habían extinguido, lo cual se torna un pretexto para que el narrador problematice el tema de las etnias y el mestizaje. Llegados a este punto, conviene recordar que la visión que plantea Clemente Palma ya había sido discutida en su polémica tesis de bachiller El porvenir de las razas en el Perú. En el cuento, sostiene:

En el año 2279 los mongoles y los tártaros, esas malditas razas amarillas, habían inundado el mundo y malogrado las razas europeas y americanas, con la mezcla de su sangre impura. No había rinconcillo del mundo a donde esa gente no hubiera llegado y estampado la huella de su maldición étnica: no había rostro que no condujera un par de ojillos sesgados y una nariz chata; no había cabeza que no estuviera cubierta de cerdosa y negra cabellera. [...] Esa raza se extendió por el mestizaje, como una hiedra inmensa que hubiera cubierto el mundo, y al cabo de tres siglos apenas había uno que otro ejemplar de raza pura. (Palma, 2006: 240)

Esta argumentación, con un aparente sustrato científico y distanciamiento de las realidades concretas de América Latina, y a través de la ficcionalización, permite a Clemente Palma replantear un discurso que fuera de actualidad en la segunda mitad del siglo XIX. De este modo Palma integra en su discurso ficcional moderno un imaginario de una sociedad que busca una identidad mimética con las sociedades europeas. Al respecto, Rodríguez Cascante nos dice:

Es así como se desarrollan ingentes esfuerzos en procura del blanqueamiento: desde el rechazo a la mezcla, siempre considerada degradante y perversa, hasta los afanes de importación humana, cuya finalidad era limpiar la sangre de las impurezas americanas. Parecerse a otro era la necesidad fundamental, por lo que se desarrolla el propósito pedagógico como vía para alcanzar la superación y poder arribar a una ansiada “equiparación” cultural. (Rodríguez Cascante, 2004: 247)

Como hemos mencionado anteriormente, este nuevo discurso de la civilización moderna tuvo como referente intelectual el Facundo de Domingo Faustino Sarmiento, y podemos corroborar de qué manera, desde la ficción, Clemente Palma evidencia estos mismos y 
cuestionables preceptos. Refiriéndose a las culturas europeas, el narrador-personaje las caracteriza de la siguiente manera:

La belleza germana, el tipo griego, la gentileza italiana, la elegancia europea, la corrección británica, la gracia española son hoy meras tradiciones de las que solo en los libros antiguos se encuentran relaciones. (Palma, 2006: 240)

En estas culturas - desaparecidas en el tiempo del relato - destaca asimismo "los bellos ideales y las bellas formas" (Palma, 2006: 242), en el cual impera un sentido estético aplicable a la interpretación del mundo. La realidad, nos propone este cuento, se observa desde una belleza idealizada, metáfora de la modernidad estética; pero también estos ideales son asumidos en constante estado de peligro, que en este cuento son asumidos como los mestizajes, pero que también podemos entenderlos como metáforas de una desenfrenada modernización industrial que daña y corrompe a los hombres.

\section{Formas y contenidos.}

A las aproximaciones planteadas en el apartado anterior quisiéramos ahora agregar los aportes del crítico José Miguel Oviedo en su "Introducción" al libro Antología crítica del cuento hispanoamericano (1830-1920). La antología la divide en I. Romanticismo; II. Realismo / Naturalismo; III. Modernismo; IV. Del Postmodernismo al Criollismo. Lo primero a destacar es la distinción que realiza entre el modernismo y el postmodernismo. También resaltamos que encabeza su lista de antologados postmodernistas con el escritor Clemente Palma. Para nuestro estudio es pertinente conocer cuáles fueron los criterios de parte de Oviedo para colocar a Palma dentro del grupo de los postmodernistas y qué entiende él por la producción modernista.

Luego de una caracterización de las narraciones románticas, realistas y naturalistas, Oviedo da las primeras pistas para una diferenciación de la prosa modernista con la producción anterior. En estas ideas preliminares el autor sostiene que en la prosa modernista se observa la presencia de la elegancia, delicadeza, sensualidad y elitismo intelectual. En su opinión, estos rasgos - y su conjunción en la prosa - fueron inexistentes en la prosa romántica, naturalista y criollista escrita en este continente. Posteriormente, ampliando su caracterización del modernismo, sobre todo en la prosa, menciona algunos otros rasgos formales y temáticos.

El movimiento es fácilmente reconocible a través de ésas y otras notas, como los juegos cromático-sonoros, el exotismo fantástico, el ocultismo paganizante y la languidez decadente. (Oviedo, 1989: 13)

Sin embargo, queremos detenernos en otro de los rasgos presentados por Oviedo, puesto que consideramos que aquí reside la confusión en su argumentación para la diferenciación entre modernismo y postmodernismo. El autor nos dice, refiriéndose a los narradores modernistas latinoamericanos:

[...] quizás por primera vez, los cuentistas se preocuparon más por la forma que por el tema: el cuento era vía de expresión agudamente personal, no el traslado de una realidad dada. (Oviedo, 1989: 13)

José Miguel Oviedo, además, complementa su afirmación al decir que en los textos propiamente modernistas se diluyen las fronteras del género cuento, aproximándose más, en cuanto a lo formal, al poema en prosa. Y derivado de este comentario y tratando de hallar una distinción temática, Oviedo vincula al relato modernista con la meditación filosófica, la divagación impresionística o al más impalpable cuento de hada (Oviedo, 1989: 13). En este 
sentido, el crítico opta por hablar en términos de sacrificio de la anécdota en favor de la riqueza verbal. Detecta en ellos, además, una tendencia a los relatos intradiegéticos y metadiegéticos, de acuerdo a sus niveles narrativos. Así, el autor nos dice:

[...] los modernistas [Gutiérrez Nájera y Amado Nervo] gustaban incorporar a sus textos el acto mismo de su elaboración. Para mostrar cómo contaban, construían relatos "hipotéticos", con historias en estado de suspensión, colgando precariamente del devaneo imaginativo del autor. (Oviedo, 1989: 24)

En oposición a este tipo de cuento, José Miguel Oviedo propone el postmodernismo como un proceso de interiorización y repliegue del propio modernismo. Oviedo dirá que el postmodernismo se preocupó por mostrar:

[...] menos adorno y más sustancia; por otro, regreso al contorno propio y aun a los ámbitos que, como el campo y la provincia, parecían haber perdido toda actualidad. El postmodernismo hace la crítica del modernismo (sobre todo la de su lenguaje), deja un poco de lado las luces deslumbrantes del festín dariano y desciende por la zona oscura de lo anormal, lo onírico o lo mágico. (Oviedo, 1989: 24-25)

Una de las primeras atingencias que observamos en esta clasificación es que el argumento de los cuentos que él considera modernistas no necesariamente debe ser visto como un elemento sacrificado en favor de lo formal. Lo que Oviedo llama vías de expresión agudamente personal en el narrador modernista nosotros las entendemos como expresión de la modernidad que se genera en un doble discurso - intimista y colectivo - . La divagación impresionista puede leerse como una crítica directa a los desajustes entre los procesos modernizadores en la sociedad latinoamericana.

Por otro lado, Oviedo parece entender el postmodernismo como otra etapa del modernismo, consecutiva temporalmente. Si bien sus rasgos formales y temáticos son acertados, consideramos que estos se dieron simultáneamente con las formas descritas anteriormente. Es decir, se trata de otro registro más de la prosa modernista. La interiorización y repliegue que menciona Oviedo se dieron de manera simultánea, sobre todo en el Perú.

\section{Juegos de la modernidad: "Don Quijote"}

Para ampliar y matizar las diversas formas simultáneas del cuento modernista en el Perú, conviene revisar algunos otros cuentos modernistas fechados tanto a finales del siglo XIX como a principios del $\mathrm{XX}$, en los que encontramos una variedad de registros argumentales $\mathrm{y}$ discursivos. Ellos dan prueba de un interés común de modernizar la narrativa peruana y que los cambios, las modernizaciones tecnológicas y sociales formaron parte de su imaginario modernista. Nos gustaría mencionar un escritor muy poco investigado. Me refiero a Carlos E. B. Ledgard (1877-1953). Su único libro de cuentos consignado se llamó Ensueños y fue publicado en 1899. El cuento que pasamos a analizar se titula "Don Quijote". La historia trascurre en Alemania, en el ambiente estudiantil de la Universidad de Heidelberg. Esta narración extradiegética se vale un narrador homodiegético, que es un estudiante alemán de esta universidad. Es interesante que este narrador se identifique como una persona, al igual que sus compañeros y compatriotas, con una educación positivista, y que por ello mismo no podía comprender la actitud del protagonista del cuento, el español Diego Javier Hernández y Pelayo, quien es apodado como Don Quijote.

Sabemos que los modernistas por lo general estaban en constante conflicto con las ideas positivistas, aunque - ya sea desde la parodia y la crítica - estas ideas se articulaban permanentemente con el discurso modernista. Para el caso de esta narración la oposición es 
oportuna, pues el narrador refiere la peripecia del protagonista desde una perspectiva de extrañeza. El personaje Don Quijote es visto como un idealista, que para el caso del cuento era lo mismo que considerarlo un demente. De allí el sobrenombre, además de su contextura delgada y débil. Este personaje no tenía ningún interés en lo material y podía desprenderse fácilmente del dinero para ayudar a sus amigos, ante lo cual el narrador exclama: "y cómo abusábamos de él!" Inmediatamente el protagonista es marginado. Su burlaban incluso de que él estuviera enamorado de la hija del dueño de la cervecería, una joven rubia llamada Graetchen. Su timidez e idealización lo llevaron a planear terminar sus estudios de doctorado, pero no para seguir una vida profesional, como ansiaban sus condiscípulos, sino volver a su pueblo en Castilla.

Vemos que este protagonista, al ser español, comparte los idealismos de los modernistas, tanto los latinoamericanos como los españoles, pero no logra liberarse de los modelos tradicionales, a los cuales ve como una salvación para aquel mundo moderno mercantilista y práctico. En este breve cuento, el amor hacia la joven Graetchen pudo ser el objeto de su felicidad, pero representó el motivo de su muerte. Uno de sus condiscípulos se burló del protagonista diciéndole que su amada se había fijado en Fritz, quien era, según el narrador, el sujeto más despreciable de Heidelberg. La burla terminó en la propuesta de un duelo de parte del protagonista, el cual se tuvo que llevar a cabo, por las insistencias de Don Quijote. Para los estudiantes, este reto a duelo les parecía cómico. Fue por ello que, siguiendo el modelo de las historias de enredos, deciden colocar bolas de algodón en lugar de balas. Lo que no esperaban era que el protagonista cayera fulminado por un ataque al corazón, producto de la impresión.

El cuento se vale de esta trama de corte satírico para mostrar las diferentes mentalidades entre la juventud europea, pero también para, desde la perspectiva del narrador alemán, instaurarse en la modernidad de dichas mentalidades. Tampoco podemos dejar de lado la construcción del modelo femenino. Si bien su participación es reducida en este cuento, la joven rubia es la representación de la seducción de otras culturas. Ella finalmente se escapa con Fritz, el peor pretendiente, pero un hombre de su comunidad. La muerte de Don Quijote, entonces, fue en vano. Ni siquiera su ideal permanece en el espíritu de sus compañeros.

Otro aspecto interesante a destacar en este cuento es la distinción étnica que se hace de los españoles y los alemanes. Al principio de la narración se insiste en su aspecto físico: "Era alto, flaco, de pelo negro e hirsuto y andar poco elegante". Calificar de "hirsuto" el cabello del protagonista, muestra cierta carga peyorativa, discriminatoria. Siendo ésta la perspectiva de un alemán, vemos cómo el tema de las razas se integra a la idea de modernidad. Si el argumento del cuento confirma que el protagonista, un español, se interesa en una joven rubia alemana, el escritor sugiere que estos ideales son pertinentes y aplicables en la sociedad peruana, la cual reclamaba un anhelo de modernidad.

\section{Espacios modernos: "El cuaderno azul"}

El cuento pertenece al escritor José Antonio Román (1873-1920) y se incluye en su conjunto titulado Almas inquietas, de 1916. Lo primero a detectar es su estructura. Este cuento sigue el modelo utilizado por Clemente Palma en su cuento "Idealismos". Se vale de un narrador homodiegético que ha encontrado en las calles el diario íntimo. De esta manera se construye una narración metadiegética, insertándose en un segundo nivel las páginas de este diario. Es interesante notar que este narrador cumple con las actitudes propias de un modernista, sobre todo en lo que se refiere a la imagen del flâneur que deambula por la ciudad en busca de instantes de felicidad. El cuento empieza diciendo: "Una espléndida noche de luna, vagando por las calles de la ciudad, hallé en la acera un cuaderno de tafilete azul con abrazaderas de níquel". En esta primera frase ya detectamos varios de las referencias constantes en el imaginario modernista. En primer lugar, es importante precisar el momento del día, la noche, 
ya que éste ofrece matices cromáticos en la percepción de la realidad. Cromatismo que se complementa con la presencia de la luna, pues ésta brinda una iluminación especial sobre los objetos, como lo es destacar el color azul - asociado a la melancolía y a la noche - y los tonos plateados de las abrazaderas de níquel - vinculado al brillo y al reflejo de los metales -. Luego tenemos la imagen del artista que vagabundea, presentado aquí como un gerundio - "vagando" - que nos sugiere una acción continua, en realización permanente. Finalmente la mención a las calles, la cual debe ser observada en ese momento propicio de una noche "espléndida". Es importante para este cuento la precisión del espacio urbano, pues veremos que las páginas del diario insertadas hablan de un espacio diferente, que entra en conflicto con la ciudad.

A diferencia del cuento de Clemente Palma, cuyas páginas del diario encontrado corresponde al testimonio trágico de un hombre, en este caso se trata del diario de una mujer. La descripción que hace el narrador de la caligrafía del diario es muy oportuna, porque nos sugiere el espíritu que va a guiar el tono de la historia insertada. Nos dice que se trata de unas páginas: "[...] cuajadas de una letra menuda, muy delgada y de rasgos complicadísimos, reveladores de una fina neurosis". Especialmente la expresión fina neurosis nos introduce en un personaje femenino en el que se conjuga la belleza y la enfermedad. Sobre todo en el periodo de entresiglos, con el desarrollo del positivismo y las ciencias de la salud, el carácter de los personajes literarios fue comúnmente asociado a enfermedades psicológicas, las cuales a su vez fueron relacionadas con la salubridad y la higiene. De esta manera encontramos a una mujer casada que describe su estado mental alterado por vivir lejos de la ciudad de Lima, en un pueblo andino cerca de la ciudad de Yauli. Ella detesta la nieve, porque siente que ésta altera sus sentidos de tal manera que la incita hacia la infidelidad.

Este tratamiento del tema de la mujer enferma en la modernidad, sin duda José Antonio Román lo recupera del libro de cuentos Dolorosa y desnuda realidad de Ventura García Calderón, que había sido publicado en 1907. La mujer de este cuento se lamenta de haberse apartado de lo que debió ser condición de esposa sometida a las convenciones sociales. Es por esa razón que ella, luego del matrimonio, acompañó a su esposo a las zonas andinas del Perú. Pero este cambio de espacio, como hemos precisado, altera su salud y su comportamiento, convirtiéndola en una mujer que no puede resistirse a los deseos de los hombres. Ella lo refiere de la siguiente manera:

Por las mañanas al contemplar en el espejo la horrible palidez que en mi rostro dejan los terrores nocturnos, reviven en mí raras ideas de desolación y muerte: creo en una horrible desgracia que amenaza a mi hogar y a cada instante, a medida que transcurren las horas y mi marido no regresa pronto, presiento no sé qué desdicha. Y si repentinamente unos brazos me enlazan por el talle, mientras unos labios ansiosos sofocan el grito de espanto que iba a lanzar, un calofrío de terror recorre mis miembros y mi cuerpo laxo, casi desfalleciente se dejan llevar sin oponer resistencia.

Esta mujer no puede resistirse al sometimiento masculino. Es interesante ver cómo en este cuento la imagen del hombre es mostrada a través de sus relaciones con la sociedad y la modernización del Perú. A ello hay que agregar otra distinción en este cuento, frente a los de Clemente Palma o García Calderón, por ejemplo, ya que aquí las referencias al Perú son evidentes y determinantes para el desarrollo de la historia. Esta mujer nos cuenta que se enamoró de su marido al verse atraída por sus bigotes rubios. Ella misma también se presenta como una mujer rubia cuando dice: "todo aquello pasa ahora en confusión por mi rubia cabecita." Aunque sin mayor profundización al respecto, vemos que, al igual que en el cuento "La última rubia" de Clemente Palma, el tema de las etnias está presente como imagen de la modernización. Por otro lado, su marido representa a las nuevas generaciones de profesionales. Su mujer lo describe así: "un joven ingeniero, había obtenido un ventajoso empleo en una mina 
cerca del pueblo de Yauli." Esta referencia es una evidente muestra de los años de auge de la minería peruana en aquel entonces y la modernización económica que vivía el país.

A esta imagen de su marido, se opone la de otro hombre que pasa por el pueblo y que va a alterar su estado emocional. Ella se siente inmediatamente seducida por la imagen de un escritor. Lo presenta de la siguiente manera:

¡Iba a caer con él! Con un cualquiera a quien apenas conozco. Me han dicho que es un espíritu culto, un literato que viaja por la cordillera recogiendo impresiones de esta vida agreste y dura. Su aspecto físico es en verdad seductor; pero su alma, ¿quién podría descifrar el enigma que encierra? Y él es muy insinuante; tiene en sus negros ojos y en su voz de un timbre armonioso, con inflexiones casi femeninas, un encanto singular.

La imagen del personaje que se sugiere aquí es la de un artista modernista. Lo podemos colegir porque se dice que es alguien que busca impresiones. Si bien no son las impresiones de la ciudad, nos muestra que el escritor de entresiglos va ampliando su espectro en el imaginario modernista. Este escritor se muestra seductor y se remarca cierta feminidad en su voz, características propias del dandy de la modernidad. Luego se dice que este personaje alterna su seducción con una imagen de hombre afectado en sus emociones, lo cual atrae aún más a la protagonista, estableciendo una suerte de identificación. Ambas son almas afectadas y les cuesta aceptar y adaptarse a los cambios de la sociedad.

Estos dos personajes se entregaron al ideal del amor. Sin embargo, dejarse llevar por la seducción carnal trajo como consecuencia la conclusión de la incompatibilidad de los ideales y la realización del amor. Por esa razón terminaron su relación violentamente y conllevó al fin de la vida de la protagonista. Ella nos dice:

A pesar de todo, una honda melancolía lacera mi alma: he fracasado lamentablemente en mi última prueba. Ahora, ya puede el desencanto tender sobre mí su negro velo, ya pueden las desesperanzas, los amargos tedios que hacen insoportable la existencia cuando está desprovista de alguna ilusión, empujarme con suavidad hacia la muerte. Estoy cansada y enferma; ya no me resta ideal alguno, así es que ya puedo buscar el consolador reposo de postrer sueño...

El ideal modernista sucumbe, inevitablemente, en la insatisfacción, en el desencanto. Es por esa razón que la muerte se convierte en una salida recurrente en este tipo de cuentos. El narrador imagina a la protagonista dejándose morir en medio de la nieve "con fúnebre gozo". Sin embargo, la muerte en sí misma también es asumida como una renovación del ideal, como una representación de ese doble discurso de la modernidad que implica vida y progreso, pero también desilusión y muerte.

La prosa de la modernidad en el Perú desde finales del XIX y principios del XX fue un claro reflejo de las expectativas que la sociedad misma mantenía y alimentaba, creando simultáneamente un imaginario contrastable con la compleja realidad en aquel periodo de cambios, pero a su vez tratando de estimular una idealización de lo que se supuso (o anhelo) debió ser el hombre moderno en el Perú.

\section{BIBLIOGRAFIA}

ESCOBAR, Alberto (1965): Patio de Letras. Lima, Caballos de Troya. 
RODRIGUEZ CASCANTE, Francisco (2004): "Modernidad e identidad cultural en América latina", Káñina, Revista de Artes y letras, Universidad de Costa Rica, vol. XXVIII, 2004, p. 237-255.

PALMA, Clemente (2006): Narrativa completa, vol. I. Lima, Pontificia Universidad Católica del Perú, 2006, p. 239.

OVIEDO, José Miguel (1989): Antología crítica del cuento hispanoamericano / 1830-1920. Madrid, Alianza Editorial.

LARRAIN Jorge (1997): "La trayectoria latinoamericana a la modernidad”, Estudios Públicos, $\mathrm{n}^{\circ} 66,1997$, p.313-333.

ZAVALETA, Carlos Eduardo y Sandro Chiri (2002): El cuento en San Marcos, (eds), Lima, Universidad Nacional Mayor de San Marcos.

(C) Ricardo Sumalavia

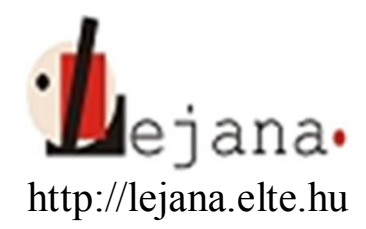

Universidad Eötvös Loránd, Departamento de Español, 1088 Budapest, Múzeum krt. 4/C

Recibido: 04 de julio de 2015

Aceptado: 13 de octubre de 2015 